\title{
ELABORAÇÃO DE IOGURTE COM ADIÇÃO DE EXTRATO AQUOSO DA SEMENTE DE MORINGA OLEÍFERA
}

\author{
P. H. F. CARDINES ${ }^{1}$, A. T. A. BAPTISTA ${ }^{1}$, R. G. GOMES $^{1}$, R. BERGAMASCO ${ }^{2}$ e A. M. S. \\ VIEIRA $^{1}$ \\ ${ }^{1}$ Universidade Estadual de Maringá, Departamento de Ciência de Alimentos \\ ${ }^{2}$ Universidade Estadual de Maringá , Departamento de Engenharia Química \\ E-mail para contato: pedrocardines@hotmail.com
}

\begin{abstract}
RESUMO - As sementes de Moringa oleifera Lam possuem um elevado conteúdo proteico e são escassos os estudos que utilizam esta semente aplicada a sistemas alimentícios. Desta forma, este trabalho teve como objetivo analisar a adição de 0, 5, 10 e $15 \mathrm{~mL}$ de extrato aquoso de semente de moringa/ Litro de iogurte natural. Também avaliou-se o índice de sinérese durante 28 dias. Foi observado que a amostra contendo a maior dosagem de extrato de moringa foi a que apresentou menores valores de sinérese, seguida das amostras contendo $10 \mathrm{~mL}, 5 \mathrm{~mL}$ e por fim a amostra controle, que apresentou as maiores perdas por esse fenômeno. Sendo assim o extrato aquoso de semente de moringa demonstrou ser uma boa alternativa para promover a redução das porcentagens de sinérese em iogurte natural.
\end{abstract}

\section{INTRODUÇÃO}

A procura crescente por alimentos que possam promover o bem estar, a saúde e, consequentemente uma melhor qualidade de vida, tem incentivado uma série de pesquisas em busca de novos componentes naturais (KIMMONS et al, 2012), impulsionando assim, o desenvolvimento de uma grande variedade de alimentos principalmente os com ênfase em funcionais (SIRÓ et al., 2006).

Estudos realizados com alimentos de origem vegetal vêm estudando a caracterização e perfil dos nutrientes presentes nas sementes de vegetais como fonte de proteína alternativa na dieta humana. O estudo de novas fontes proteicas com o objetivo de utilizar suas propriedades tecnológicas no processamento de alimentos pode ser justificado por razões de ordem econômica e tecnológica (RODRIGUES, et al., 2012).

A combinação de um produto suplementado com proteínas e fermentado por microorganismos probióticos pode gerar um produto com propriedades tecnológicas, sensoriais e funcionais que atendam a demanda por produtos saudáveis. A suplementação do leite para a fabricação de iogurte, com diferentes tipos de proteínas, melhora o valor nutricional do produto e 
afeta principalmente a formação da estrutura do gel do iogurte, alterando propriedades como textura, firmeza, viscosidade, retenção de água e separação do soro (ISLETEN et al., 2006).

A Moringa oleífera é uma espécie vegetal da família Moringaceae, originária do nordeste indiano, amplamente distribuída na Índia, Egito, Filipinas, Ceilão, Tailândia, Malásia, Burma, Paquistão, Singapura, Jamaica e Nigéria (GALLÃO et al., 2006) de fácil cultivo e adaptação no Brasil, principalmente no nordeste.

A maioria dos estudos envolvendo as sementes de moringa trata de características floculantes, devido aos seus componentes de baixo peso molecular que vem sendo utilizadas no tratamento de águas. GHEBREMICHAEL et al. (2005) determinou esses componentes com peso molecular variando de 6,5 a $30 \mathrm{KDa}$.

Levando em consideração seu reconhecido valor medicinal e como hortaliça não convencional, as sementes se destacam por serem ricas em proteínas e lipídeos $(\sim 70 \%$ de ácido oléico), porém existe a necessidade de estudos que focalizem a viabilidade seu uso, direcionados também à sua exploração comercial. Devido a tais informações e a carência de trabalhos sobre as sementes de moringa como possível fonte de insumo para a indústria alimentícia, este trabalho teve como principal objetivo avaliar a influência do extrato aquoso de semente de moringa adicionado ao iogurte natural visando seu potencial como agente formador de corpo.

\section{MATERIAL E MÉTODOS}

A parte experimental deste trabalho foi realizada no Laboratório de Gestão, Controle e Preservação Ambiental, do Departamento de Engenharia Química - DEQ, da Universidade Estadual de Maringá - UEM e as sementes de Moringa foram doadas pela Universidade Federal do Sergipe - SE.

\subsection{Obtenção do extrato aquoso de semente de moringa}

As sementes foram armazenadas sob refrigeração para manter ao máximo suas características inicias até o momento da análise.

As sementes de moringa foram descascadas manualmente e secas em estufa com circulação de ar a $40^{\circ} \mathrm{C}$, até peso constante, e então foram trituradas em processador com água numa proporção de $3 \mathrm{~g}$ de semente para $1 \mathrm{~L}$ de água destilada. Esta solução não apresentou alterações bruscas de $\mathrm{pH}$, o qual se manteve entre 6,5 e 7,0. Em seguinte as sementes trituradas foram mantidas sob agitação em agitador magnético por 30 minutos e posterior filtração a vácuo. 


\subsection{Produção do iogurte}

Foi utilizada uma cultura de micro-organismos comercial, composta por culturas de Lactobacillus acidophilus LA- $5^{\circledR}$, Bifidobacterium BB-12 ${ }^{\circledR}$ e Streptococcus thermophilus (Chr Hansen).

O leite integral tipo $\mathrm{B}$, foi aquecido a $85^{\circ} \mathrm{C}$, mantido em um banho termostatizado por 15 minutos, com o objetivo de reduzir a carga microbiana, inativar enzimas, reduzir a quantidade de oxigênio dissolvido, criando condições de microaerofilia favoráveis ao crescimento da cultura e desnaturação parcial das proteínas do leite, o que contribui para a melhor coagulação do leite ao final da fermentação. Posteriormente, o leite foi resfriado em banho de água e gelo até temperatura próxima de $43^{\circ} \mathrm{C}$, seguido da adição do extrato de Moringa em três concentrações diferentes, 5,10 e $15 \mathrm{~mL}$ e um processamento sem adição, chamado de controle. Em seguida foi realizada a adição da cultura láctica em condições assépticas. $\mathrm{O}$ produto foi incubado a $42^{\circ} \mathrm{C} \mathrm{em}$ estufa. O tempo de fermentação do iogurte foi calculado a partir do início da inoculação, até se obter o valor de $\mathrm{pH}$ próximo a 4,6. Terminada a fermentação, foi feito um resfriamento inicial até aproximadamente $20^{\circ} \mathrm{C}$, e a quebra do coágulo por agitação manual durante 30 segundos. Em seguida, foi realizado o resfriamento final e os iogurtes foram armazenados à temperatura de $5^{\circ} \mathrm{C}$, até realização das análises.

\subsection{Suscetibilidade a sinérese}

A susceptibilidade a sinérese foi medida pelo método descrito por Modler e Kalab (1983), em triplicata. Amostras de 25g foram centrifugadas (Centrifuga refrigerada MPW - 351R, MPW MED. INTRUMENTS) a $2500 \mathrm{G}$ por 10 minutos a uma temperatura de $5^{\circ} \mathrm{C}$. O sobrenadante límpido (soro) e a massa restante foram pesados em balança analítica separadamente. A diferença entre a massa total $\left(\mathrm{m}_{\mathrm{t}}\right)$ e a massa do sobrenadante $\left(\mathrm{m}_{\mathrm{s}}\right)$ corresponde a sinérese, que foi expressa em porcentagem $(\% \mathrm{~ms} / \mathrm{mt})$. As análises foram realizadas no período de 7, 14, 21 e 28 dias de armazenamento, sendo que as amostras foram acondicionadas em recipientes com tampa e armazenados em geladeira.

\section{RESULTADOS E DISCUSSÃO}

\subsection{Suscetibilidade a sinérese}

Durante o armazenamento de produtos lácteos pode-se observar o fenômeno de sinérese, ou seja, a expulsão gradativa do soro devido à contração do gel decorrente de alta temperatura de incubação, tratamento térmico do leite por tempo prolongado ou pelo baixo teor de sólidos totais. 
Os resultados da susceptibilidade a sinérese estão expressos na Tabela 1, representados pela porcentagem de liberação de líquido em relação ao peso inicial da amostra.

Tabela 1 - Percentuais de sinérese do iogurte submetido a diferentes tratamentos durante quatro semanas.

\begin{tabular}{|c|c|c|c|c|c|}
\hline & Semanas & 1 & 2 & 3 & 4 \\
\hline \multirow{4}{*}{ 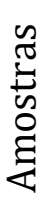 } & Controle & $28,50 \pm 1,80^{a}$ & $26,81 \pm 1,36^{a}$ & $24,90 \pm 1,93^{a}$ & $23,50 \pm 0,82^{a}$ \\
\hline & M05 & $26,03 \pm 1,54^{\mathrm{ab}}$ & $24,70 \pm 1,40^{a b}$ & $22,01 \pm 1,41^{\mathrm{ab}}$ & $21,60 \pm 0,93^{b}$ \\
\hline & M010 & $24,40 \pm 0,30^{a b}$ & $23,27 \pm 0,30^{\mathrm{ab}}$ & $21,18 \pm 0,78^{a b}$ & $20,16 \pm 1,47 b$ \\
\hline & M015 & $23,42 \pm 0,70^{b}$ & $21,96 \pm 0,20^{b}$ & $17,46 \pm 0,47^{b}$ & $17,21 \pm 0,04^{c}$ \\
\hline
\end{tabular}

As médias seguidas pela mesma letra não diferem estatisticamente entre si, para cada coluna separadamente. Foi aplicado o Teste de Tukey ao nível de $5 \%$ de probabilidade.

As amostras foram identificadas como MO5 (contendo $5 \mathrm{~mL}$ de extrato de moringa por litro de iogurte), MO10 (contendo $10 \mathrm{~mL}$ de extrato de moringa por litro de iogurte), MO15 (contendo $15 \mathrm{~mL}$ de extrato de moringa por litro de iogurte) e a amostra controle que não foi adicionada de extrato de moringa.

Nota-se na Tabela 1 que em todos os tratamentos contendo extrato de moringa a liberação de líquido foi menor se comparada à amostra controle. Sendo a maior diferença observada na terceira semana, comparando a amostra controle com o tratamento MO15. Esse fato pode estar ligado ao aumento do teor proteico, já que as sementes de moringa apresentam em média $40 \%$ de seu peso total em proteínas (GALLÃO, 2006), resultando em iogurtes com capacidade de retenção de soro significativamente maiores, ou seja, menores valores de sinérese.

O armazenamento proporcionou maior estabilidade na dessoragem dos iogurtes, resultados semelhantes foram observados por RAMIREZ-SANTIAGO et al., (2010), em analises realizadas em iogurte acrescido de fibras dietéticas solúveis.

STIJEPIĆ et al. (2013), encontraram valores para amostras de iogurte natural com índices de sinérese variando na faixa de 26 a 30\%, demonstrando assim que o acréscimo do extrato aquoso de semente de moringa colaborou de forma significativa para a redução do índice de sinérese.

Através do estudo realizado acrescentando-se extrato de moringa no iogurte do tipo natural nota-se que os melhores resultados, ou seja, os menores índices de sinérese foram constatados para os maiores volumes de extrato acrescentados, resultando em um produto de melhor aspecto visual, já que a migração de soro para a superfície foi menor.

\section{CONCLUSÃO}

Com base no estudo desenvolvido foi possível constatar que o extrato aquoso de semente de moringa colaborou de forma significativa para a redução dos índices de sinérese em iogurte do tipo natural. Sendo um possível substituinte de melhoradores de textura e gomas, tendo em vista que a moringa é um ingrediente natural de baixo custo e fácil produção. 


\section{AGRADECIMENTOS}

Os autores agradecem ao apoio financeiro recebido pelo Conselho Nacional de Desenvolvimento Científico e Tecnológico (CNPQ), Coordenação de Aperfeiçoamento de Pessoal de Nível Superior (CAPES) e a Fundação Araucária.

\section{REFERÊNCIAS}

CINBAS, A, YAZICI, F. Effect of the addition of blueberries on selected physicochemical and sensory properties of yoghurts. Food technol. Biotechnol. v. 46 (4), p. 434-441, 2008.

GALLÃO, MI, DAMASCENO, LF AND BRITO, ES. Avaliação química e estrutural da semente de Moringa. Revista Ciência Agronômica, v. 37, p. 106-109, 2006.

GHEBREMICHAEL，KA，GUNARATNA，KR，HENRIKSSON， H，BRUMER，H AND DALHAMMAR, G. A simple purification and activity assay of the coagulant protein from Moringa oleifera seed. WaterResearch, v. 39, p. 2338-2344, 2005.

ISLETEN, M, KARAGUL-YUCCER, Y. Effects of dried dairy ingredients on physical and sensory properties of nonfat yogurt. Journal of Dairy Science, v. 89(8), p. 2865-2872, 2006.

KIMMONS, J, JONES, S, MCPEAK, HH, BOWDEN, B. Developing and Implementing Health and Sustainability Guidelines for Institutional Food Service. Advances in Nutrition. v. 3, p. 337$342,2012$.

MODLER, HW, KALAB, M. Microstructure of yogurt stabilized with milk proteins. Journal of Dairy Science, v. 66, p. 430-437, 1983.

RAMIREZ-SANTIAGO, C, RAMOS-SOLIS， L， LOBATO-CALLEROS， C, PEÑAVALDIVIA, C, VERNON-CARTEL, J AND ALVAREZ-RAMIRES, J. Enrichment of stirred yogurt with soluble dietary fiber from Pachyrhizuserosus L. Urban: Effect on syneresis, microstructure and rheological properties. Journal of Food Engineering, v. 101, p. 229-235, 2010.

RODRIGUES, IM, COELHO, JFJ AND CARVALHO, MG. Isolation and valorisation of vegetable protein from oilseed plants: Methods, limitations and potential. Journal of Food Engineering. v. 109(3), p. 337-346, 2012. 
SIRÓ, I, KÁPOLNA, E, KÁPOLNA, B AND LUGASI, A. Functional food. Product development, marketing and consumer acceptance-a review. Appetite, v. 51, p. 456-467, 2008.

STIJEPIĆ, M, GLUŠAC, J, ĐURĐEVIĆ-MILOŠEVIĆ, D AND PEŠIĆ-MIKULEC, D. Physicochemical characteristics of soy probiotic yoghurt with inulin additon during the refrigerated storage. Romanian Biotechnological Letters, v. 18 (2), p. 8077-8085, 2013. 